\title{
JUSTIFICAÇÃO PÚBLICA: A FUNÇÃO DA IDEIA DE ESTRUTURA BÁSICA DA SOCIEDADE EM RAWLS
}

\author{
Denis Coitinho Silveira* \\ deniscoitinhosilveira@gmail.com
}

RESUMO O objetivo principal deste artigo é estabelecer uma reflexão sobre a função da ideia da estrutura básica da sociedade (basic structure of society) para a justificação pública (public justification) dos princípios morais na teoria da justiça como equidade de John Rawls, principalmente nas obras Political Liberalism (PL, Lecture VII) e Justice as Fairness: A Restatement (JF, I, § 4, 9; II, § 15, 16), com a intenção de identificar um modelo ético coerentista e pragmatista de justificação, analisando o papel da categoria de justiça de fundo (background justice) neste contexto justificacional.

Palavras-chave Justificação pública, estrutura básica da sociedade, justiça de fundo

Abstract The main aim of this paper is to provide a reflection about the function of the idea of the basic structure of society for a public justification of the moral principles in the John Rawls's theory of justice as fairness, especially in works such as Political Liberalism (Lecture VII) and Justice as Fairness: A Restatement (I, $\S 4,9 ; I I, \S 15,16)$, with a view to identifying a coherentist and pragmatical justification model, analyzing the role of the background justice category in this justificational context.

* Professor do Departamento de Filosofia da Universidade Federal de Pelotas. Bolsista de Produtividade do CNPq. Artigo recebido em 9/03/2010 e aprovado em 15/12/2010.

KRITERION, Belo Horizonte, nº 123, Jun./2011, p. 197-211. 

justice

Keywords Public justification, basic structure of society, background

\section{Situando o Problema}

A teoria da justiça como equidade de Rawls pode ser vista como uma teoria moral que busca a justificação pública dos princípios morais, afirmando que a justificação é superior a conexão entre justificação e verdade; negando, porém, que teorias epistêmicas possam garantir a verdade objetiva de fatos morais. Rawls defende uma teoria coerentista de justificação em ética que enfatiza que uma crença p é justificada como parte de um sistema coerente de crenças p's, afastando-se do fundacionalismo ${ }^{1}$. A coerência se dá entre os princípios de justiça, teoria da justiça como equidade e juízos morais ponderados em equilíbrio reflexivo amplo (wide reflective equilibrium). Os princípios são construídos a partir da teoria da justiça como equidade (justice as fairness), e servem para mostrar quais juízos morais podem ser tomados como corretos (considered judgments). Por sua vez, estes juízos morais ponderados servem de referência para a formulação da teoria. Este modelo não é inferencial, pois garante a correção dos juízos e princípios morais a partir de uma teoria moral que se apresenta como melhor candidata para cumprir a sua função de garantia da estabilidade (stability) social a partir da ideia de uma sociedade como um sistema equitativo de cooperação. Sua estratégia de justificação está em assegurar que os fatos morais - quais instituições sociais, políticas e econômicas são justas, por exemplo - são produto de um processo de construção em que agentes racionais, sob determinadas condições formais e substanciais, estabelecem um acordo sobre os princípios para regular suas relações, identificando a estrutura básica da sociedade como objeto primeiro da justiça como equidade. Como Rawls não defende uma posição intuicionista ou naturalista, não se percebe o uso da categoria de fato moral (ponto objetivo absoluto para justificação de juízos e princípios morais). Entretanto, os deveres e direitos assegurados pela estrutura básica podem ocupar o lugar dos fatos morais, pois servem de orientação aos agentes em seu âmbito público de atuação. A objetividade dos princípios morais construídos não consiste na defesa de uma or-

1 Para o fundacionalismo, uma crença moral $p$ é justificada em caso de $p$ ser igualmente (a) fundamentado e (b) baseado em um tipo de inferência de crenças fundamentadas. O coerentismo moral assegura que uma crença moral $p$ é justificada na medida em que ela seja parte de um sistema coerente de crenças e a coerência em $p$ 's explica parcialmente porque se defende $p$. Ver BRINK, 1989: 101-104. 
dem moral independente do próprio acordo, mas na aceitação de um ponto de vista social imparcial que pressupõe certos valores políticos (ideal de cidadania democrática e dever de civilidade no âmbito dos elementos constitucionais essenciais e das questões de justiça básica). Creio que a ideia da estrutura básica da sociedade, bem como o uso do conceito de justiça de fundo, apontam para a possibilidade de superação da controvérsia desenvolvida entre realistas e antirrealistas, pois o problema moral não necessita resumir-se na comprovação ou não de um fundamento absoluto para os juízos morais em um âmbito privado $^{2}$. A alternativa proposta por Rawls está em considerar a justificação moral em um âmbito público, recusando tanto a posição realista forte como a posição antirrealista compreendida como não-cognitivista, cética ou emotivista, com a defesa da objetividade desses juízos a partir da capacidade das pessoas serem mais ou menos razoáveis, bem como subsumindo alguns valores públicos substanciais para recusar o relativismo moral ${ }^{3}$. A justificação pública visa oferecer uma alternativa ao problema da justificação epistemológica que exigiria uma teoria tradicional do significado para dar conta da verdade dos juízos e princípios morais, na qual o significado do dito teria um correspondente ontológico, apelando para um modelo pragmatista de justificação, em que o significado dos enunciados morais será determinado por seu uso, isto é, no seu contexto de garantia da estabilidade social justa ${ }^{4}$.

2 O debate entre realistas e antirrelistas pode ser expresso assim: (1) O Realismo, na sua versão robusta (robust moral realism), afirma que os juízos morais implicam em descrever fatos morais à luz dos quais sejam verdadeiros ou falsos. São verdadeiros se forem corretos, correspondendo a alguma ordem de referência que seja externa à crença do agente (metafísica, psicológica, epistemológica); (2) O Antirrelismo nega que os fatos morais tenham uma existência independente da consciência do agente. Isto pode implicar em (2.1) negar a existência de propriedades morais independentes (não-cognitivismo e ceticismo) ou em (2.2) aceitar a existência de propriedades morais dependentes da consciência do agente (emotivismo, subjetivismo, relativismo, idealismo, construtivismo). $\mathrm{O}$ atual estado da questão aponta o construtivismo rawlseano como um tipo de antirrealismo que nega (2.1), sendo identificado como cognitivista, mas que aceita (2.2), pois a equidade é determinada pelos resultados de uma decisão imaginária coletiva de agentes racionais e razoáveis para o estabelecimento dos princípios sob uma situação de imparcialidade, decisão esta que requer uma atividade mental. Ver BOYD, 2008: 163-165.

3 Segundo Onora O'Neill, o construtivismo de Rawls se diferencia do posicionamento antirrealista ao reivindicar o papel de construção dos princípios pelos agentes morais, recusando a concepção emotivista, bem como refutando o posicionamento intuicionista ou comunitarista. Ver O'NEILL, 2003: 348. Segundo Catherine Audard, a teoria da justiça como equidade não faz uso de uma fundamentação naturalista, não podendo ser considerada como um realismo moral; entretanto, isto não significa a adoção de alguma forma de relativismo moral. Ver AUDARD, 2007: 48 e 55.

4 No artigo "The Independence of Moral Theory" (1975), Rawls defende a independência da teoria moral em relação à epistemologia, colocando entre parênteses o problema da verdade moral e investigando sobre as concepções morais substantivas que se defenderia em situações definidas. A saída é encontrada no procedimento do equilíbrio reflexivo, em que se procura encontrar um esquema de princípios que sejam coerentes com os juízos ponderados dos indivíduos, sendo que estes princípios caracterizam a sensibilidade moral dos agentes, descrevendo seu senso de justiça e possuem as seguintes características: generalidade, universalidade, ordenação, publicidade e estabilidade. Eles não são verdadeiros, mas possuem uma validade pragmatista. Ver CP (Collected Papers): 288-292. É por isto que Rawls reivindica que sua teoria da justiça é apenas política, não tendo pretensões metafísicas em sentido estrito. Este é o 


\section{Justificação Pública e Estrutura Básica da Sociedade}

A função da ideia de uma justificação pública (public justification) é compreender a ideia de justificação de forma adequada a uma concepção política de justiça para uma sociedade que se caracteriza pelo pluralismo razoável (reasonable pluralism) ( $J F$, I $\S$ 9.1: 26). Esta ideia de justificação pública está conectada a outra ideia fundamental da justiça como equidade que é a de uma sociedade bem-ordenada (well-ordered society), pois tal sociedade é organizada por uma concepção política de justiça, e isto significa que: (1) é uma concepção moral específica para a estrutura básica da sociedade (basic structure of society); (2) não é uma doutrina abrangente, sendo apenas uma concepção razoável em que seus princípios expressam valores políticos; (3) está restrita à ideias fundamentais que se encontram na cultura política pública de uma sociedade democrática, como, por exemplo, a ideia de uma sociedade como um sistema equitativo de cooperação social (society as a fair system of cooperation) e a ideia de cidadãos como livres e iguais (free and equal persons) $(\mathrm{JF}, \mathrm{I}, \S 9.1: 26-27)^{5}$.

O processo de uma justificação pública significa que os juízos políticos devem ser justificados entre os cidadãos, e isto representa convencê-los por meio da razão pública, isto é, através de raciocínios e inferências adequadas com questões políticas básicas, recorrendo apenas a determinados valores políticos que sejam razoáveis aos outros ${ }^{6}$. Esta justificação pública depende de um acordo de juízos políticos pelo menos no que diz respeito aos elementos constitucionais essenciais, a saber: (1) os princípios fundamentais que determinam a estrutura geral do governo e seu processo político; prerrogativas do legislativo, executivo e judiciário; limites da regra da maioria e (2) direitos e liberdades básicos iguais de cidadania (direito de votar e participar da política, liberdade de pensamento, associação, consciência e garantia do estado de direito) (JF, I § 9.3: 28). Esta justificação pública tem por base tomar como ponto de partida as ideias fundamentais contidas na cultura política para

argumento central do artigo "Justice as Fairness: Political not Metaphysical" (1985) em CP: 388-414. Ver, também, o artigo "Outline of a Decision Procedure for Ethics" (1951) em CP: 6-7.

5 Daniels defende que o papel da teoria moral está em mostrar quais os princípios que são mais razoáveis que outros de uma maneira independente dos juízos morais dos agentes. Assim, o ponto central da justificação em Rawls é estabelecido na aceitação de uma teoria da justiça que coloca à prova as considerações morais tendo como finalidade uma sociedade bem-ordenada. Ver DANIELS, 1996: 22.

6 Para Scanlon, a norma da justificação pública é estabelecer uma especificação de um tipo de justificação que cidadãos devem estar aptos a realizar em uma discussão política especificando os elementos constitucionais essenciais e as questões de justiça básica, derivando uma norma da conduta política a partir de uma reivindicação sobre como instituições democráticas poderiam ser estáveis de uma forma correta. Ver SCANLON, 2003: 160. 
formar uma base pública de justificação, em que todos os cidadãos (tomados como racionais e razoáveis) podem endossar a partir de suas doutrinas abrangentes (concepções filosóficas, religiosas, morais) ${ }^{7}$. Dessa maneira, temse um consenso sobreposto (overlapping consensus) de doutrinas abrangentes razoáveis, e isto implica em assumir uma concepção política em equilíbrio reflexivo (reflective equilibrium). Como a teoria da justiça como equidade não é uma doutrina fundacionalista, não tem a necessidade de provar a verdade desses juízos a partir de um intuicionismo racional ou de um racionalismo transcendental, basta que se alcance o consenso sobreposto, que é objetivo, a partir do uso público da razão para o encontro do comensurável ${ }^{8}$

Um dos aspectos fundamentais da teoria da justiça como equidade é identificar a estrutura básica da sociedade como objeto primeiro em uma concepção contratualista de justiça. A estrutura básica é compreendida como a forma pela qual as principais instituições se harmonizam em um sistema e a forma específica de essas instituições distribuírem direitos e deveres fundamentais. As partes da estrutura básica da sociedade são a constituição política, as formas legalmente reconhecidas de propriedade, a organização da economia e a natureza da família ( $P L$, VII, $\S 1: 258)$. A estrutura básica é o sistema social de fundo em que tomam parte as atividades de associações e indivíduos, sendo a estrutura básica o que assegura a justiça de fundo ( $J F, \mathrm{I}, \S 4.1: 10)$. Em $T J$ (A Theory of Justice), Rawls tratou da estrutura básica da sociedade como objeto primordial, mas não tratou de esclarecer as razões da escolha desse projeto e suas consequências. Para prestar o esclarecimento do significado da estrutura básica, Rawls oferece uma síntese do que é a justiça como equidade, a saber, que é um contrato social hipotético, que é um acordo entre todos os cidadãos e é um acordo entre os cidadãos considerados como membros de uma sociedade e não como indivíduos que ocupam uma determinada posição; as partes (parties) são compreendidas como pessoas morais, livres e iguais e o conteúdo do acordo consiste nos princípios de justiça que possuem a tarefa de regular a estrutura básica da sociedade ( $P L$, VII, $\S 1: 258-259)$. Desse modo, há uma transferência da equidade das circunstâncias para a equidade

7 Samuel Freeman aponta que o modelo de justificação pública em Rawls está ancorado no conceito de autonomia política, que é alcançada quando os cidadãos justificam suas ações a partir de regras equitativas e as legitimam sob uma base de razão pública sob condições de igual poder político. Isto significa que não é necessário que os cidadãos endossem todas as regras, apenas as que podem ser razoavelmente endossadas a partir da própria capacidade de razoabilidade dos cidadãos tomados como livres e iguais. Ver FREEMAN, 2007a: 399-401.

8 Fred D'Agostino mostra como Rawls se utiliza de um método de comensurabilidade (commensuration) para refutar tanto o intuicionismo como o utilitarismo em razão de sua incomensurabilidade, de forma a permitir que pessoas livres e iguais de uma sociedade democrática possam estabelecer uma base de valores comuns para a estrutura básica da sociedade. Ver D'AGOSTINO, 2007: 195-196. 
dos princípios aceitos, revelando a justiça procedimental em seu nível mais elevado9 . A estrutura básica da sociedade é considerada como objeto central da justiça como equidade porque: 1- como as partes são consideradas como pessoas morais, livres, iguais e racionais, existem bons motivos para analisar a estrutura básica como objeto primeiro, 2- de acordo com as características dessa estrutura, o acordo original e suas condições de executabilidade devem ser entendidos de uma forma específica que possibilite sua diferenciação de outros tipos de acordo, 3- esse procedimento leva em conta a natureza social das relações humanas, segundo uma visão kantiana, e 4- os princípios devem construir uma forma ideal de estrutura básica (PL, VII, $\S 1: 259)^{10}$.

A característica especial da justiça como equidade está em começar com a estrutura básica e, posteriormente, desenvolver outros princípios de maneira sequencial. Isto se evidencia ao estabelecer o contraste entre o utilitarismo e a justiça como equidade. No utilitarismo clássico, o princípio de utilidade aplica-se de maneira igual a todas as formas sociais e às ações individuais. $\mathrm{Na}$ justiça como equidade, os princípios de justiça não são adequados para uma teoria geral, pois apenas exigem da estrutura básica que estabeleça certas liberdades fundamentais iguais para todos, e garanta, também, que as desigualdades sociais e econômicas resultem no maior benefício para os mais desfavorecidos em um contexto de oportunidades equitativas (PL, VII, $\S 2$ : $261)^{11}$. Sua unidade teórica é propiciada pela sequência apropriada da teoria do contrato social que visa a responder a questão de como os princípios que se aplicam a diferentes objetos devem ser articulados entre si. O que está em questão é a possibilidade de encontrar uma sequência apropriada de tipos de objetos e estabelecer uma suposição de que as partes de um contrato social devem proceder conforme essa sequência, ressaltando que os princípios de cada acordo posterior devem ser subordinados aos acordos anteriores, ou ajustados a eles por determinadas regras de prioridade ( $P L, \mathrm{VII}, \S 2: 262)$.

9 Em $T J$ (§ 22), Rawls afirma que as circunstâncias da justiça podem ser descritas como as condições normais sobre as quais a cooperação humana é tanto possível como necessária. A referência a este tipo de argumento é encontrada em David Hume (A Treatise of Human Nature, bk. III, PT. II, sec. ii e An Enquiry Concerning the Principles of Morals, sec.III, pt. I). Isto pode significar que o projeto ético rawlseano pretende estabelecer uma teoria compatibilista entre os modelos teleológico e deontológico, interconectando situações concretas e ideais nos procedimentos justificacionais.

$10 \mathrm{Em} \mathrm{JF}$, Rawls aponta que a principal característica de uma concepção política é a ideia da estrutura básica da sociedade compreendida enquanto objeto primeiro da justiça, em razão do importante papel das instituições sociais e da natureza dos princípios para garantir a justiça de fundo (JF, II, § 15.1: 52).

11 Para Munoz-Dardé, a teoria de Rawls pretende ser uma resposta às doutrinas éticas utilitaristas, utilizandose de elementos de deliberação moral que sejam convenientes para uma sociedade democrática bemordenada. Ver MUNOZ-DARDÉ, 2000: 60. Ver, também, em GUILLARME, 1999: 102. 
Tanto o utilitarismo como o libertarianismo, bem como outras teorias gerais, rejeitam a ideia de que princípios primeiros de justiça orientem a estrutura básica da sociedade ( $P L$, VII, § 3: 261). O libertarianismo, por exemplo, é caracterizado como defensor do Estado mínimo, que é limitado à proteção contra o uso da força, contra o roubo e a garantia de contratos. Nessa concepção teórica, qualquer Estado com poderes mais amplos viola os direitos fundamentais dos indivíduos. O objetivo do libertarianismo é investigar de que forma um Estado mínimo pode surgir de uma situação perfeitamente justa por meio de uma série de passos, passos esses moralmente permissíveis e sem que nenhum deles viole os direitos de ninguém. Parte da hipótese do estado de natureza, em condições justas e iguais, sem instituições. Em seguida, definem-se certos princípios básicos de justiça que organizam a aquisição e a transferência de posses. Na concepção libertariana, o Estado é interpretado como qualquer outra associação privada, surgindo em um processo histórico hipotético perfeitamente justo. Rawls distingue o processo histórico hipotético (as-if historical), em que todos devem obedecer aos princípios de justiça de aquisição e transferência e podem obedecer a eles, como a um processo que é hipotético, mas pode ser realizado, do processo não-histórico hipotético (as-if nonhistorical), como o procedimento que leva ao acordo na posição original que não pode ocorrer ( $P L, \mathrm{VII}, \S 3: 264)$. A teoria libertariana considera o Estado como uma associação privada, rejeitando as ideias fundamentais do contrato social, não apresentando espaço para uma teoria de justiça que inclua a estrutura básica ${ }^{12}$.

O objetivo do contraste apresentado entre as concepções do libertarianismo e do utilitarismo com a visão da justiça como equidade é ressaltar a importância especial da estrutura básica e responder por que é razoável procurar princípios específicos para regulá-la ( $P L$, VII, § 3: 265). A partir da importância da ideia da estrutura básica pode-se identificar que o liberalismo rawlseano não pode ser confundido com o libertarianismo ou com o utilitarismo por não contar apenas com os interesses privados do agente para a fundamentação dos princípios morais. O liberalismo político pretende estabelecer um critério po-

12 O que Rawls está ressaltando é que o libertarianismo não pode ser compreendido enquanto uma teoria do contrato social em razão de apenas afirmar as liberdades individuais ( $P L$, VII, § 3: 265). Para Baynes, a teoria rawlseana contrasta com o libertarianismo (como em Nozick) ao considerar a estrutura básica como objeto primeiro da justiça, de forma que as instituições sociais de fundo possuem a finalidade de garantir as expectativas e oportunidades dos membros da sociedade. Ver em BAYNES, 1992: 161. 
lítico autossustentado para alcançar um consenso sobreposto entre as diversas doutrinas que afirmam uma concepção de bem ${ }^{13}$.

\section{Background Justice (Justiça de Fundo)}

Sendo a estrutura básica da sociedade a forma em que as instituições sociais e políticas podem assegurar um sistema de cooperação social, garantindo deveres e direitos e regulando a divisão das vantagens, pode-se dizer que é esta estrutura básica justa o que assegura a justiça de fundo. Para analisar a importância da categoria de background justice, Rawls interpreta a estrutura básica da sociedade como objeto primeiro da justiça em um horizonte de contrato social kantiano. Considera-se, em primeiro lugar, que as relações pessoais devem ser desenvolvidas ao longo do tempo a partir de acordos livres alcançados de forma equitativa e que sejam plenamente respeitados ${ }^{14}$. O objetivo das instituições pertencentes à estrutura básica é garantir condições de fundo justas em que as ações individuais e associacionais podem ser efetivadas (PL, VII, § 4: 266). Rawls oferece um exemplo para o entendimento da questão colocada em que a distribuição que resulta de transações de mercado em geral não é justa, a menos que a distribuição anterior de renda e riqueza seja justa. Assim, as condições para a justiça básica podem ser dissolvidas, mesmo que ninguém tenha agido de forma injusta ou que tenha consciência de que o resultado de trocas distintas afeta as oportunidades dos demais. Por isso, a necessidade de estabelecer como objeto a estrutura básica da sociedade para assegurar a equidade, o que implica em uma justificação externalista que está conectada com o internalismo ${ }^{15}$.

13 Freeman defende que é pela condição de publicidade que a justiça como equidade garante maior estabilidade que o libertarianismo ou utilitarismo, pois os princípios são publicamente conhecidos e justificados. Ver em FREEMAN, 2003: 22. Para Nagel, o que define o liberalismo político de Rawls é a sua pretensão de consenso sobreposto, isto é, que pretende estabelecer uma concepção política autossustentada (free-standing) que possibilite uma compatibilidade com as diversas doutrinas compreensivas (abrangentes). Ver NAGEL, 2003: 84.

14 Para Onora O'Neill, Rawls compreende sua concepção de justiça como equidade em TJ em estreita relação com a concepção construtivista de Kant, incorporando uma justiça procedimental pura para demonstrar que os princípios são resutados de um processo de construção na posição original por agentes racionais, livres e iguais. Ver O'NEILL, 2003: 349-351. Ver, também, BIRD-POLLAN, 2009: 12-13.

15 Uma usual distinção entre o internalismo e o externalismo aponta que: o internalismo afirma que a justificativa de uma crença $\mathbf{p}$ por um sujeito $\mathbf{S}$ se dá em termos de $\mathbf{S}$ possuir razões para considerar $\mathbf{p}$ verdadeiro. Em termos de filosofia moral, a crença moral $\mathbf{p}$ é justificada pela motivação $\mathbf{m}$ do sujeito $\mathbf{S}$; por sua vez, o externalismo afirma que a justificativa de uma crença $\mathbf{p}$ por um sujeito $\mathbf{S}$ pode se dar em termos de $\mathbf{S}$ considerar $\mathbf{p}$ confiável (ou legítimo). Em termos morais, a crença moral $\mathbf{p}$ pode ser afirmada independentemente da motivação moral $\mathbf{m}$ do agente S. Ver SMITH, 2008: 231-233. Na justiça como equidade, os princípios morais (e juízos) não são justificados por serem verdadeiros e nem por estarem conectados apenas com a motivação do agente. Eles são justificados, também, por garantirem a estabilidade social justa, sendo um motivo externo ao agente. Sendo a estrutura básica da sociedade 
Rawls destaca quatro pontos essenciais para o entendimento da categoria de background justice neste processo de justificação pública. A justiça de fundo, então, possui as seguintes características: 1- ela requer um ponto de vista social (social point of view), 2- necessita de instituições específicas para garantir a equidade (lei e governo), 3- suas regras devem ser políticas (com função prática e não matemática), 4- e devem orientar a vida econômica e social. Assim, são necessárias regras públicas para o estabelecimento da justiça de fundo. Levando-se em consideração apenas a conduta individual e de associações para os acordos equitativos, é impossível afirmar a equidade de tais acordos, sem consideração das características da estrutura básica e em que medida ela consegue manter a justiça de fundo. Isto quer dizer que a equidade depende das condições sociais, tais como a oportunidade equitativa ( $P L$, VII, $\S 4: 266-7)$. As condições equitativas existentes podem ser extintas gradualmente, mesmo sem a ação injusta específica de ninguém, não sendo necessário para a preservação da justiça básica da sociedade que todos acreditem que estão agindo de maneira equitativa ( $P L$, VII, $\S 4: 267)$. Dessa forma, não existem normas absolutas que seja possível impor aos indivíduos para poderem impedir a desestruturação da justiça de fundo, pois as normas não podem ser complexas demais, devendo restringir-se ao escopo político ( $P L, \mathrm{VII}, \S 3$ : 267-8). Assim, chega-se a uma divisão entre os tipos de normas sociais e as formas institucionais para a realização das normas. A questão essencial é estabelecer como a estrutura básica deve realizar os ajustes para a preservação da justiça básica. O objetivo é estabelecer uma divisão de trabalho institucional entre a estrutura básica e as normas que têm aplicabilidade imediata sobre os indivíduos e associações e que devem ser observadas ( $P L$, VII, $\S 4: 268-9)^{16}$.

Uma questão que se revela importante é a reflexão sobre a necessidade de uma teoria da justiça levar em consideração a maneira como se formulam

necessária para a garantia da equidade, percebe-se que não é apenas o esquema mental do agente que conta para a justificação da regra, tendo que se valer de uma referência exterior ao agente. Para Thomas Pogge, esta justificação externa não afirma a existência de verdades morais; entretanto, considera que tanto o princípio liberal de legitimidade como o dever de civilidade podem ser compreendidos como sendo parte da verdade moral, no sentido da afirmação da objetividade de determinados deveres e direitos, não implicando a afirmação de seu valor de verdade. Ver POGGE, 2007: 161-177.

16 A categoria de background parece desempenhar um papel relevante no modelo de justificação rawlseano. Em primeiro lugar, pode ser tomada como o conjunto de doutrinas abrangentes que formam o imaginário de uma sociedade (background culture), como o conjunto de doutrinas religiosas, morais e filosóficas da sociedade civil ( $P L$ I, § 2.3: 14). Também, pode ser tomada como tendo um importante papel para o estabelecimento do mundo social correto que está pressuposto aos cidadãos tomados como pessoas livres e iguais (background justice). A sociedade bem-ordenada é apresentada como um mundo social possível a partir da categoria do consenso sobreposto de doutrinas abrangentes razoáveis. Assim, os princípios de justiça devem conduzir a um esquema de instituições básicas, isto é, a um mundo social próprio conveniente ao seu fim, que é a equidade (fairness) (PL II, § 5.4: 77). 
os objetivos e aspirações das pessoas, e essa tarefa faz parte da estrutura mais ampla de pensamento, significando o horizonte de uma concepção de justiça. A abrangência da estrutura básica é ressaltada por formar uma cultura pública compartilhada pelas pessoas com determinadas concepções de bem (PL, VII, $\S 5: 269)$. A estrutura básica permite desigualdades sociais e econômicas dos cidadãos em função de suas origens sociais, dotes naturais e oportunidades acidentais, e isso é benéfico para a manutenção da cooperação social efetiva. A função definitiva da teoria da justiça é regular as desigualdades na perspectiva de vida dos seus cidadãos, decorrentes da posição social original, como vantagens naturais e contexto histórico, pois, ao longo do tempo, essas desigualdades possuem efeitos cumulativos, destruindo, assim, a possibilidade da justiça como equidade ( $P L, \mathrm{VII}, \S 5: 271 ; J F, \mathrm{II}, \S 16.1: 55)$.

As instituições da estrutura básica são justas quando satisfazem os princípios que pessoas morais, livres e iguais adotariam em uma situação equitativa, e isso caracteriza a justiça como equidade. Os princípios que devem ser satisfeitos são o princípio da liberdade e o princípio da igualdade de oportunidades e da diferença (equal liberty principle and difference/fair equality principle). $\mathrm{O}$ acordo original é entendido como hipotético e não-histórico, porque é marcado pelas condições da estrutura básica que quer garantir a equidade na sociedade. A estrutura básica é entendida como o sistema social mais inclusivo que determina a cultura de fundo. Essa situação equitativa entre indivíduos considerados como pessoas morais, livres e racionais não deve ser influenciada por contingências sociais e naturais desiguais. Acordos dessa natureza, que levam em consideração as situações concretas, seriam acordos efetivos, e não iriam além das contingências naturais e sociais, não tendo condições de especificar um critério independente (PL, VII, § 6: 271-2). É por isso que as partes (parties) na posição original (original position), consideradas como pessoas livres, morais e racionais, não devem ter conhecimento dos aspectos contingentes, a fim de não permitir que este conhecimento seja utilizado para a determinação dos princípios. Essa é função do véu da ignorância (veil of ignorance), a saber, garantir a equidade na escolha dos princípios de justiça para a estrutura básica da sociedade. Por isso, o contrato social fundamentado na posição original sob o véu da ignorância deve ser considerado hipotético e não-histórico, pois representa um acordo racional de deliberação em condições ideais que expressam razoabilidade. Este modelo é analítico, pois a posição original é caracterizada suficientemente para que, a partir da natureza das partes e da situação enfrentada, se possa descobrir que concepção de justiça é favorecida pelo equilíbrio de razões. O conteúdo da justiça deve ser encontrado pela razão, quer dizer, em função da resolução do problema do 
acordo que é apresentado na posição original. Esta situação inicial estabelece uma perspectiva de representar e unificar os elementos formais do pensamento moral em uma espécie de construção praticável e vivida, com o objetivo de empregar esses elementos para determinar os primeiros princípios que são mais razoáveis. Considerando a estrutura básica da sociedade como objeto da teoria, fica ressaltado o papel primordial da posição original que, através de seu véu da ignorância, abstrai das condições históricas e contingentes para o estabelecimento de princípios equitativos pelas partes consideradas como pessoas morais (PL, VII, $\S 6: 275)^{17}$.

$\mathrm{O}$ acordo inicial realizado na posição original sob o véu da ignorância destaca um caráter específico da estrutura básica da sociedade e, dessa maneira, distingue-se dos demais tipos de acordo. Em relação aos acordos específicos, tem-se as partes deliberando a partir do conhecimento de vantagens e agindo de acordo com esse conhecimento (PL, VII, § 7: 275). Esses acordos particulares são realizados a partir de um contexto de configurações existentes e previsíveis de relações no interior da estrutura básica, sendo essas as configurações que oferecem uma base para os cálculos do contrato. Neste contrato social o modelo de escolha é profundamente diferente em razão de três fatos, a saber: 1- o pertencer à sociedade já é algo dado, 2- não possui conhecimento de como seria não pertencer à sociedade e 3- a sociedade não possui fins da mesma forma que as associações e indivíduos. Em relação ao primeiro fato, as partes, na posição original, reconhecem que sua participação na sociedade já está dada. A tarefa apresentada é chegar a um acordo sobre os princípios relacionados com a estrutura básica, supondo que as partes viverão toda a vida nesta sociedade ( $P L$, VII, $\S 7: 277)$. Em relação ao segundo fato, a posição inicial reconhece que a situação das partes, como seres razoáveis e responsáveis, só é possível em função da vida em sociedade. Em relação ao terceiro fato, não existem fins sociais, somente os fins socais estabelecidos pelos princípios de justiça. Isso caracteriza especificamente a justiça como equidade, ao estabelecer qual a função da estrutura básica no esquema da posição original enquanto um projeto racional ( $P L$, VII, $\S 7: 277-280)^{18}$.

17 Para Bedau, isso revela o caso específico da justiça procedimental pura (pure procedural justice), uma vez que a justiça como equidade não se vale de um critério absoluto (justiça procedimental perfeita) e nem se vale apenas de um critério formal (justiça procedimental imperfeita) que não garante a correção do resultado. Ver BEDAU, 1999: 104. Ver esta distinção em PL, II, § 5: 72-73.

18 Para Dombrowski, a teoria rawlseana possui um caráter plural e eminentemente político do liberalismo, na medida em que pretende estabelecer um consenso sobreposto sobre doutrinas compreensivas, separando o horizonte político do não-político e afirmando os fins políticos da sociedade. Ver DOMBROWSKI, 2001: 13. 
O aspecto social das relações humanas passa a se refletir no conteúdo dos princípios de justiça e isso é essencial para o entendimento a respeito da estrutura básica. Em primeiro lugar, o princípio da diferença não estabelece distinção entre o que é adquirido pelos indivíduos enquanto membros da sociedade e o que seria adquirido se não fossem membros da sociedade ( $P L$, VII, § 8: 278). Em segundo lugar, os princípios de justiça estabelecem de que forma os títulos de propriedades são adquiridos em troca de contribuições para associações ou, também, a outras maneiras de cooperação no interior da estrutura básica ( $P L$, VII, § 8: 279). Em terceiro lugar, as partes são consideradas pessoas morais, livres e iguais que possuem uma concepção do bem e senso de justiça. Essa liberdade e igualdade das pessoas morais necessitam de uma forma pública, e o conteúdo dos dois princípios de justiça satisfaz a publicidade, pois é aplicado diretamente à estrutura básica da sociedade $(P L$, VII, § 8: 280-1) $)^{19}$.

Uma concepção de justiça como equidade deve incorporar uma forma ideal para a estrutura básica da sociedade ao determinar as questões distributivas, além do elemento de justiça procedimental pura, a partir da qual os resultados sociais devem ser orientados. Uma questão essencial é levantada a respeito do papel específico da estrutura básica, a saber, a partir de que princípio as pessoas morais, livres e iguais podem aceitar a argumentação de que as desigualdades sociais e econômicas decorrem da sorte ou das contingências históricas ou naturais? Como as partes se consideram como pessoas morais, livres e iguais, consideram que todos devem ter uma parcela igual de bens primários, incluindo renda e riqueza; entretanto, devem levar em consideração os requisitos de organização e eficiência econômica (PL, VII, § 9: 281-2). A estrutura básica deve permitir desigualdades econômicas e organizacionais, desde que estas desigualdades melhorem a situação de todos, especialmente aquela dos menos privilegiados, seguindo uma coerência com a liberdade igual e a igualdade equitativa de oportunidade. Dessa maneira, as partes chegam ao princípio da diferença. Observa-se, então, que os dois princípios da justiça, quando operam juntos, incorporam um elemento fundamental de justiça procedimental

19 Para Freeman, a publicidade (publicity) é uma categoria central em uma teoria moral contratualista, implicando na ideia de uma aceitação geral dos princípios através das relações sociais, o que conduz a uma base pública de justificação. Ver FREEMAN, 2007b: 5-43. McCarthy afirma que o objetivo do liberalismo rawlseano é o de alcançar uma base pública de justificação com o uso da estratégia de iniciar com as ideias compartilhadas da cultura pública e trabalhar via um equilíbrio reflexivo em direção a uma concepção política de justiça que poderia servir de foco para um consenso sobreposto e, então, alcançar a estabilidade. Esta dimensão de justificação pública em uma esfera do razoável revela um liberalismo que possui uma primazia da perspectiva do observador (primacy to the observer's perspective) com base na ideia de tolerância. Ver McCARTHY, 1994: 60-63. 
pura na repartição das partes distributivas. Esta é a insuficiência e o limite da justiça procedimental pura, pois não estabelece o que é seu conteúdo distributivo, não estabelecendo o que deve ser objeto de distribuição $(P L, \mathrm{VII}, \S 9$ : 282). Em função desse raciocínio, identifica-se que os princípios de justiça e, em especial, o princípio da diferença, aplicam-se aos princípios públicos e às pessoas que regulam as desigualdades sociais e econômicas. O princípio da diferença é aplicado, por exemplo, na tributação de renda e propriedade, na política fiscal e econômica e no contexto institucional das transações específicas. Os princípios de justiça não exigem a distribuição igual, mas estabelecem critérios para uma divisão igual de bens primários, visando à eliminação das desigualdades existentes, a partir da cooperação social que, em uma situação de melhora, deve atingir os menos favorecidos. Os princípios de justiça especificam uma forma ideal para a estrutura básica, forma essa que restringirá e ajustará os processos institucionais e procedimentais (PL, VII, § 9: 284). Aqui está o limite e a insuficiência de uma teoria puramente procedimental, pois não conta com princípios estruturais para uma ordem social justa ${ }^{20}$. O que está sendo proposto é o ponto de vista substancial que, livre dos limites puramente procedimentais, quer atingir a equidade em uma sociedade e garantir a justiça de fundo ( $P L$, VII, $\S 9: 285)$.

\section{Considerações Finais}

No final da conferência VII do $P L$, Rawls procura responder as objeções de Hegel à teoria do contrato social e isto é esclarecedor para se compreender o alcance justificacional de sua teoria. As críticas de Hegel baseavam-se na crítica da absolutização da particularidade, na identificação do Estado com uma associação privada, no conteúdo do direito público ser determinado por interesses privados, na sociedade civil ser absolutizada, e no não reconhecimento da natureza social dos seres humanos (PL, VII, § 10: 286). Rawls responde a essas objeções afirmando que o objetivo primeiro da justiça como equidade é a estrutura básica da sociedade, com o objetivo de estabelecer a justiça básica. A posição original caracteriza-se por ser um acordo equitativo entre pessoas livres, morais e racionais, que podem chegar a um acordo racional em termos de uma noção de bens primários (primary goods). O que

20 Rawls pretende oferecer uma alternativa ao princípio paretiano de eficiência, indo mais além deste princípio através do princípio da diferença (segunda parte do segundo princípio), que estabelece que a melhora de uns significa a melhora para todos e, em especial, para os que se encontram em uma situação de maior desvantagem. Dessa forma, a teoria da justiça como equidade supera o liberalismo clássico ao incorporar uma real preocupação com as liberdades reais e com uma distribuição justa. 
está em jogo neste tipo de acordo que especifica os princípios para a estrutura básica é que apresenta diversas características de outros acordos dentro dessa estrutura. Rawls responde à objeção sobre a ausência de uma natureza social do indivíduo em que, na posição original, se pode valorizar a natureza social dos seres humanos. Ralws esclarece que sua teoria se diferencia de outras teorias contratualistas, pois deseja estabelecer uma divisão de trabalho entre as operações da estrutura básica na manutenção da justiça de fundo e a definição e imposição pelo sistema legal de normas que se aplicam a indivíduos e associações (PL, VII, § 10: 286).

Dessa forma, pode-se identificar que a justificação dos princípios morais é alcançada a partir de uma referência teleológica, na medida em que a estrutura básica da sociedade é tomada como critério de correção, garantindo a justiça de fundo (background justice). O papel da categoria de estrutura básica é orientar quais os princípios que serão construídos em um âmbito público para a garantia da estabilidade, construção esta que conta com o uso público da razão e possibilita um consenso sobreposto para a fragmentação moral. Assim, sua função é possibilitar uma referência objetiva para os juízos e princípios morais, servindo de critério fundamental para uma justificação pública, critério este que é publicamente conhecido e reconhecido. Ele não conta como um fato moral em sentido estrito, servindo para se contrapor ao relativismo e emotivismo, mas possui a função de fato moral para a determinação dos juízos e princípios. Dessa forma, não seria possível ver uma proximidade entre a teoria ética rawlseana e um tipo de realismo que não defende a existência de uma ordem externa à consciência do agente?

\section{Referências bibliográficas}

AUDARD, Catherine. John Rawls. McGil-Quen's University Press, 2007.

BAYNES, Kenneth. The Normative Grounds of Social Criticism: Kant, Rawls, Habermas. Albany: SUNY Press, 1992.

BEDAU, Adam. Social Justice and Social Institutions. In: The Philosophy of Rawls: a collection of essays. RICHARDSON; WEITHMAN (Eds.). New York: Garland, 1999, p. 91-107.

BIRD-POLLAN, Stefan. Rawls: Construction and Justification. Public Reason, 2009, 1 (2): 12-30.

BOYD, Richard. "How to Be a Moral Realist". In: SHAFER-LANDAU, R.; CUNEO, T. (Eds.). Foundations of Ethics: An Anthology. Oxford: Blackwell, 2008: 163-185. BRINK, David. Moral Realism and the Foundations of Ethics. Cambridge: Cambridge University Press, 1989. 
D'AGOSTINO, Fred. “The Legacies of John Rawls". In: The Legacy of John Rawls. BROOKS; FREYENHAGEN (Eds.). London: Continuum, 2007.

DANIELS, Norman. Justice and Justification: Reflective Equilibrium in Theory and Practice. Cambridge: Cambridge University Press, 1996.

DOMBROWSKI, D. Rawls and Religion: the case for political liberalism. Albany: Suny Press, 2001.

FREEMAN, S. Introduction: John Rawls - An Overview. In: FREEMAN (Ed.). The Cambridge Companion to Rawls. Cambridge University Press, 2003, p. 1-61. . Rawls: Routledge Philosophers. London: Routledge, 2007a.

. The Burdens of Public Justification: constructivism, contractualism, and publicity. Politics, Philosophy, Economics, 2007b, 6: 5-43.

GUILLARME, Bertrand. Rawls et l'Égalité Démocratique. Paris: PUF, 1999.

McCARTHY, Thomas. "Kantian Constructivism and Reconstructivism: Rawls and Habermas in Dialogue". Ethics, vol. 105, n. 1, October, 1994: 44-63.

MUNOZ-DARDÉ, V. La Justice Sociale: le libéralisme égalitaire de John Rawls. Paris: Nathan, 2000.

NAGEL, Thomas. Rawls and Liberalism. In: FREEMAN (Ed.). The Cambridge Companion to Rawls. Cambridge: Cambridge University Press, 2003, p. 62-85.

O'NEILL, Onora. Constructivism in Rawls and Kant. In: FREEMAN (Ed.). The Cambridge Companion to Rawls. Cambridge University Press, 2003, p. 347-367.

POGGE, Thomas. "On Justification". In: John Rawls: His Life and Theory of Justice. Oxford: Oxford University Press, 2007, p. 161-177.

RAWLS, J. A Theory of Justice. Cambridge, Mass: Harvard University Press, 1971. . Political Liberalism. New York: Columbia University Press, 2005. . Justice as Fairness: A Restatement. E. Kelly (Ed.). Cambridge: Harvard University Press, 2001.

. Collected Papers. Ed. S. Freeman. Cambridge: Harvard University Press, 1999.

. Outline of a Decision Procedure for Ethics (1951). In: CP: 1-19.

. The Independence of Moral Theory (1975). In: CP: 286-302.

. Justice as Fairness: Political not Metaphysical (1985). In: $C P: 388-414$.

SCANLON, T. M. Rawls on Justification. In: FREEMAN (Ed.). The Cambridge Companion to Rawls. Cambridge: Cambridge University Press, 2003, p. 139-167.

SMITH, Michael. The Externalist Challenge. In: SHAFER-LANDAU, R.; CUNEO, T. (Eds.). Foundations of Ethics: An Anthology. Oxford: Blackwell, 2008: 231-242. 
